\title{
Analysis and Control of Flow Parameters through Sluice Gate in Dam
}

\author{
Sudip Basack, Ghritartha Goswami, Prandeep Deka, Partha Pratim Borah, Nikos Mastorakis
}

\begin{abstract}
Controlling the discharge through a gravity dam by means of sluice gate is quite common technique. Although extensive theoretical and experimental studies on discharge parameters are available, most of these studies reported sedimentation and river-bed conditions resulting in reduced discharge through a dam, although limited research has focused on controlling and adjusting the discharge considering practical scenario. This paper presents a simplified analytical model applied to a typical case study on a typical dam in western India which was used the lift irrigation technique for improving the discharge. The approach focuses on the parametric studies for predicting the variations in discharge ratio employing a range of geometrical parameters such as area and aspect ratio of the individual sluice gates and their total number. It was found that the discharge is largely affected by minor alteration in these parameters. A set of important conclusions was drawn from the entire study.
\end{abstract}

Keywords-Analytical modeling, dam, discharge, sluice gates.

\section{INTRODUCTION}

$\mathbf{H}_{s}$ draulic structures have diversified applied functions such as flood control, distribution of stored water and most importantly providing constructive ecological conditions, for which the analytical aids available in daily operation are rare. A better prediction of the flow near the dam structures would be beneficial to optimum performance of all the tasks for which the dam is constructed.

Flow through a side sluice gate is governed by the equations of spatially varied flow with decreasing discharge. Sluice-gate discharges for various gate openings have been studied by numerous researchers. Henry [1] studied the

This work is based on the field based investigation carried out by Ghritartha Goswami, the second author herein, as a part of his academic research curriculum at Nagpur University, wherein the photographs and other related field data was collected with the permissions from concerned authorities at the Water Resource Department, Nagpur, Government of Maharashtra, India.

Sudip Basack is Principal of Elitte College of Engineering at Sodepur, Kolkata 700113, INDIA (corresponding author phone: +91-8617715761; e-mail: basackdrs@hotmail.com).

Ghritartha Goswami, was with Nagpur University, Maharashtra and Assam Kaziranga University, Jorhat 785006, Assam, INDIA. He is now with the Scholar's Institute of Technology and Management, Guwahati 781035, Assam, INDIA (e-mail: goswami.ghritartha@gmail.com).

Prandeep Deka is with Extramarks Education India Private Limited, Guwahat, Assam, INDIA (e-mail: prandeep.deka2509@gmail.com).

Partha Pratim Borah is with Eko Delivery, Jorhat 785006, Assam, INDIA (e-mail: parthaborah500.pb@gmail.com).

Nikos Mastorakis is with the Technical University of Sofia, English Language Department of Engineering, Sofia, Bulgaria mastor@tu-sofia.bg diffusion of submerged jet downstream to a normal sluice gate and developed a useful correlation for discharge coefficient under

Free and submerged flow conditions. This was later confirmed by Rajaratnam and Subramanya [2]. Panda [3] and Tanwar [4] related the discharge coefficient to the Froude number, the ratio of flow depth to the side sluice gate opening, and the ratio of tail water depth to the gate opening. In case of a normal sluice gate, the elementary discharge coefficient has been found to be a function of channel flow depth for freeflow conditions, while for the submerged flow condition, the ratio of crest width to gate opening is important. The latter is also applicable to a broad-crested sluice gate $[5,6]$ proposed relevant equations for both free and submerged flows as well as criteria for the submergence. The characteristics of a combined flow over weirs and below sluice gates of equal contraction are discussed by Abdelazim [7] using various geometrical combinations. The flow through rivers and resulting scouring was studied by Bhattacharya et al [8]. The discharge characteristics of combined weirs and gate structure were studied as well. The study revealed a major influence of flow and geometrical parameters on the discharge. The airwater interface in the channel was referred to as the free surface [9]. Spulveda [10] proposed various calibration methods for discharge coefficient of submerged sluice gates; a value of contraction coefficient as 0.611 was found to yield satisfactory results. Daneshmand et al. [11] performed classical hydrodynamic analysis to arrive at specific solutions relevant to free surface flow. Water surface was found to be typically smooth for a freely emerging jet of water from a sluice gate, and for submerged flow, the surface profile is usually quite rough [12]. Mansoor [13] classified sluice gates as normal, side and skew, depending on its alignment with channel axis. Some studies can be also found in [14] and [15] on water waves by Francesco Gallerano et all. A sluice gate placed oblique to the flow direction was found to be more efficient. However, typical hydrological case studies conducted in India is rather limited [16].

The study focused in this paper is based on the Kawlewada dam located in Gondia district of Maharashtra and is a part of Dhapewada lift irrigation project, India. The site was located at the global coordinates of $21^{\circ} 26^{\prime} 28^{\prime \prime} N$ latitude and $79^{\circ} 52 ' 52^{\prime \prime} E$ longitude. A sketch of the study area is portrayed in Fig.1. It is pragmatic that the Dhapewada lift irrigation project was not efficient due to reduction in the flow of the Wainganga River during the summer season [17]. In 
order to investigate the effectiveness of Dhapewada lift irrigation project in terms of discharge with the reduced flow and to maintain the ecological balance at the downstream side of the dam, the present study deals with a simplified analytical modelling approach, with relevant computation and interpretation.

The discharge through the dam was allowed through a series of rectangular sluice gates shown in Figures 2 and 3. The area, aspect ratio and number of gates have been varied and the resulting variations in the total downstream discharges are studied in detail.

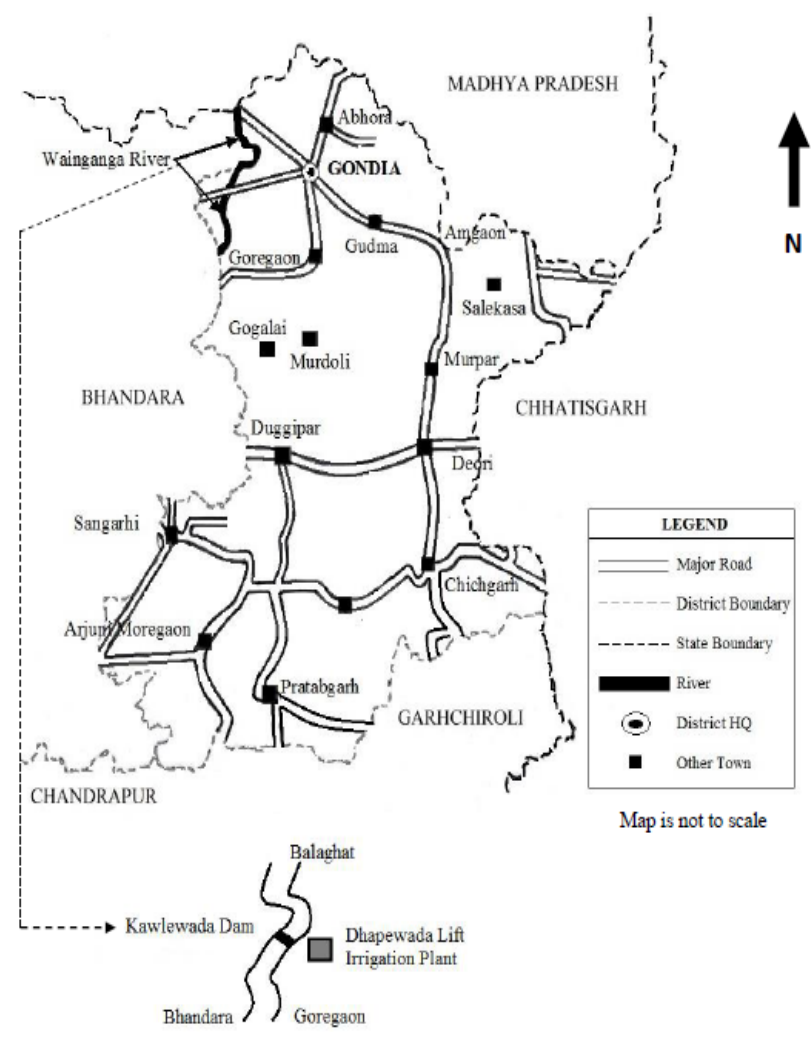

Fig.1 Site location of study area for Kawlewada dam.

\section{ANALYSIS}

First, the net discharge through the sluice gates was calculated (see Fig. 4) using the following correlation:

$$
Q_{\text {gate }}=(a . b \cdot N) \cdot v
$$

Where, $a$ and $b$ are lengths and width of the one gate opening and $N$ is the number of gates, respectively. The parameter $v$ is the average velocity of fluid flow, and is defined as [18]:

$\nu=C_{d}(2 \mathrm{gy})^{0.5}$

Where, $C_{d}$ is the coefficient of discharge, $g$ is the gravitational acceleration and $y$ is the gate opening. The parameter $C_{d}$ is given by [16]:

$C_{d}=C_{c} /\left(1+C_{c} y / a\right)^{0.5}(3)$
Where, $C_{c}$ is the contraction coefficient.

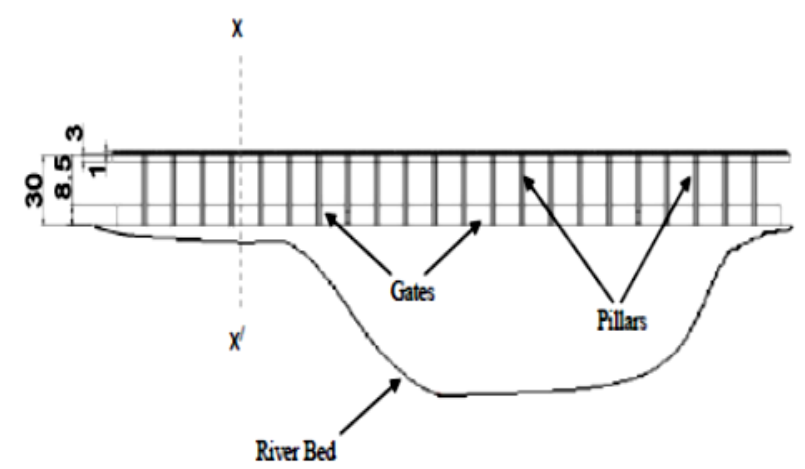

(a)

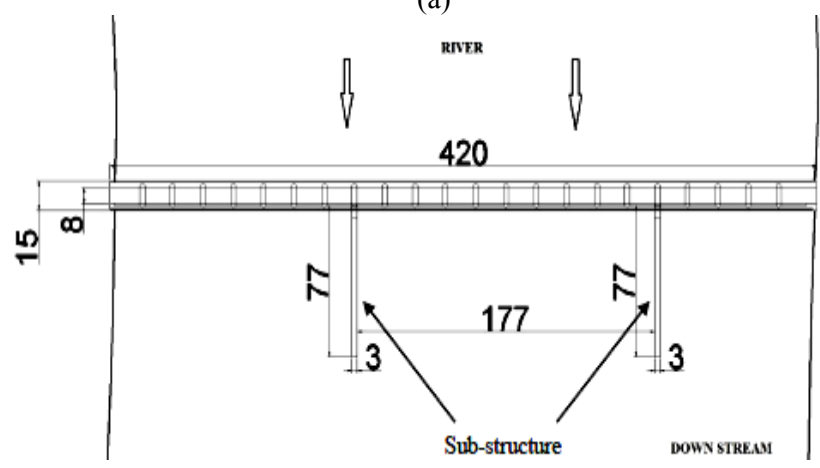

(b)

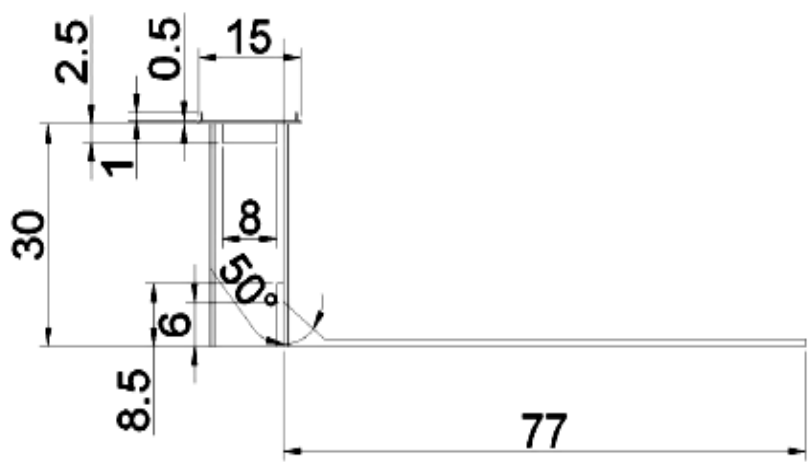

(c)

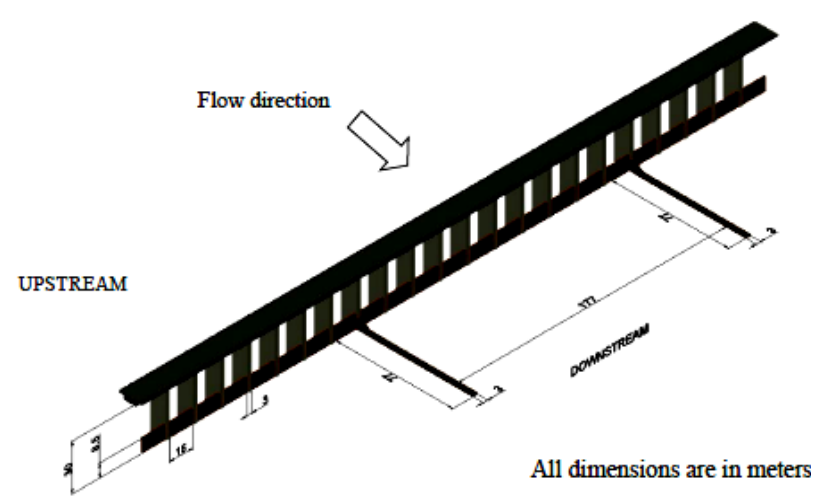

(d) 
Fig.2 The Kawlewada dam: (a) Front view, (b) Top view, (c) Cross section on $\mathrm{AA}^{\prime}$, and (d) Isometric view.

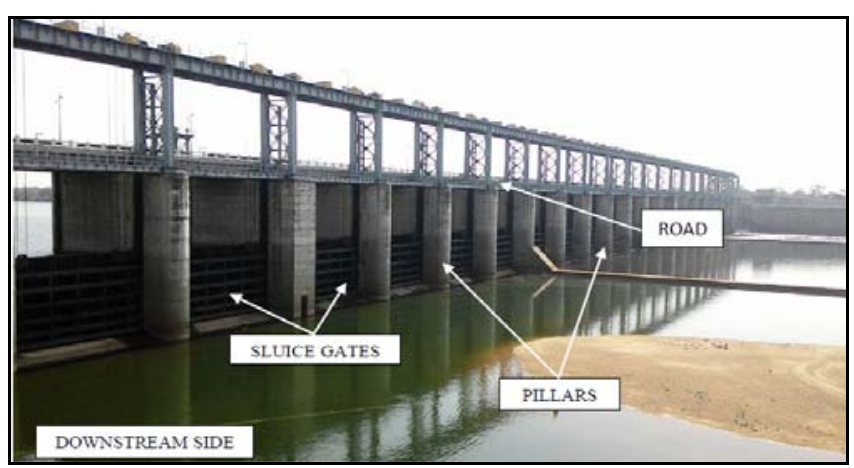

Fig.3 Photographic view of Kawlewada dam (Taken by: Ghritartha Goswami).

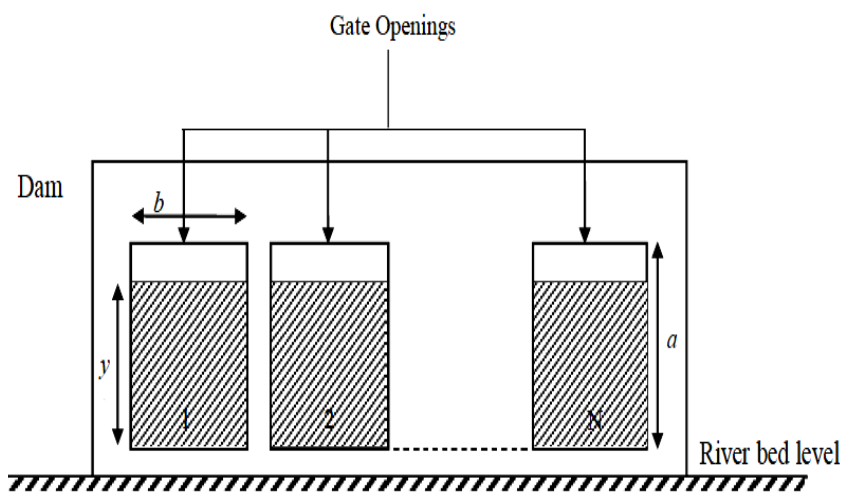

Fig.4. Illustration of geometric parameters of sluice gate.

\section{RESULTS AND DISCUSSIONS}

The variation of the discharge ratio $R_{Q}$ is studied with respect to the area ratio $R_{A}$, the aspect ratio $a / b$ and the number of gates $N$. The range of variation of the input parameters has been presented in Table I.

\section{A. Formulations}

The discharge ratio $R_{Q}$ and the area ratio $R_{A}$ are defined as:

$$
\begin{aligned}
& R_{Q}=Q_{\text {gate }} / Q_{0} \\
& R_{A}=A_{\text {gate }} / A_{\text {dam }}
\end{aligned}
$$

Where, $A_{\text {gate }}=(a, b, N)$ and $A_{\text {dam }}=(L . H)$

And $Q_{0}$ is the net upstream discharge through the river without dam

\section{B. Parametric Studies}

In case of the Kawlewada dam in the Dhapewada lift irrigation project, the input parameters taken are:

$$
\begin{aligned}
& L=\text { Length of the dam }=420 \mathrm{~m} \\
& H=\text { Height of the dam }=30 \mathrm{~m}
\end{aligned}
$$

$$
Q_{0}=40.19 \times 10^{3} \mathrm{~m}^{3} / \mathrm{s}[15]
$$

\begin{tabular}{|c|c|c|}
\hline $\begin{array}{c}\text { Area } \\
\text { ratio } \\
\left(R_{A}\right) \\
\end{array}$ & $\begin{array}{c}\text { Aspect ratio } \\
(a / b)\end{array}$ & $\begin{array}{c}\text { Number of gates } \\
(N)\end{array}$ \\
\hline \multirow{5}{*}{0.01} & 0.50 & $10,12,14,16,18$ \\
\hline & 0.75 & $10,12,14,16,18$ \\
\hline & 1.00 & $10,12,14,16,18$ \\
\hline & 1.25 & $10,12,14,16,18$ \\
\hline & 1.50 & $10,12,14,16,18$ \\
\hline \multirow{5}{*}{0.02} & 0.50 & $10,12,14,16,18$ \\
\hline & 0.75 & $10,12,14,16,18$ \\
\hline & 1.00 & $10,12,14,16,18$ \\
\hline & 1.25 & $10,12,14,16,18$ \\
\hline & 1.50 & $10,12,14,16,18$ \\
\hline \multirow{5}{*}{0.03} & 0.50 & $10,12,14,16,18$ \\
\hline & 0.75 & $10,12,14,16,18$ \\
\hline & 1.00 & $10,12,14,16,18$ \\
\hline & 1.25 & $10,12,14,16,18$ \\
\hline & 1.50 & $10,12,14,16,18$ \\
\hline \multirow{5}{*}{0.04} & 0.50 & $10,12,14,16,18$ \\
\hline & 0.75 & $10,12,14,16,18$ \\
\hline & 1.00 & $10,12,14,16,18$ \\
\hline & 1.25 & $10,12,14,16,18$ \\
\hline & 1.50 & $10,12,14,16,18$ \\
\hline \multirow{5}{*}{0.05} & 0.50 & $10,12,14,16,18$ \\
\hline & 0.75 & $10,12,14,16,18$ \\
\hline & 1.00 & $10,12,14,16,18$ \\
\hline & 1.25 & $10,12,14,16,18$ \\
\hline & 1.50 & $10,12,14,16,18$ \\
\hline
\end{tabular}

Considering value of $C_{c}$ to be $0.611, a$ to be $10 \mathrm{~m}$ and $y$ to

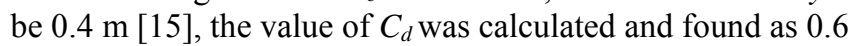

Table I: Input parameters for case study

using Eq. (3) above. Thus, the velocity $v$ was found as 8.40 $\mathrm{m} / \mathrm{s}$.

The variation of discharge ratio $R_{Q}$ with respect to aspect ratio $a / b$ for different values of $R_{A}$ and $\mathrm{N}$ has been depicted in Fig. 5. It has been observed that when the aspect ratio, area ratio and number of gates varies it ranges of $0 \leq a / b \leq 1.5,1 \leq$ $R_{A} \leq 5$ and $10 \leq N \leq 18$ respectively, the discharge ratio $R_{Q}$ varies from 0.35 to 2.6 . It has also been observed that an increase in aspect ratio initiated the parameter $R_{Q}$ to increase linearly till a peak value is attained following a stabilizing trend. The peak value is observed to attain an aspect ratio of $a / b=0.5$. Such observation may be justified by the fact that an optimization of the discharge yielded this particular value of aspect ratio resulting from Equations (1), (2) and (3).

The variation of the discharge ratio $R_{Q}$ versus the area ratio $R_{A}$ for different values of $a / b$ and $N$ is shown in Fig.6. As observed, a linear trend of variation took place. A slight nonlinear variation was also noted when the area ratio $R_{A}$ exceeds a value of 3 , specifically for $N=10$ and 12 . The lines are observed to originate from the origin and progressively diverged. Such pattern of variation may be justified by the fact that a progressively increasing area has initiated a linearly increasing discharge through the gate, as per Equation (1).

Variation of the parameter $R_{Q}$ with respect to $N$ for different values of $a / b$ and $R_{A}$ are shown in Fig.7. As observed, the variation is linearly increasing commencing 
from the origin. A variation in the value of $a / b$ did not influence the divergence of the line significantly. Such trend is justified with the fact that increasing number of gates produced a proportionate rise in the discharge as per the Equation (1).

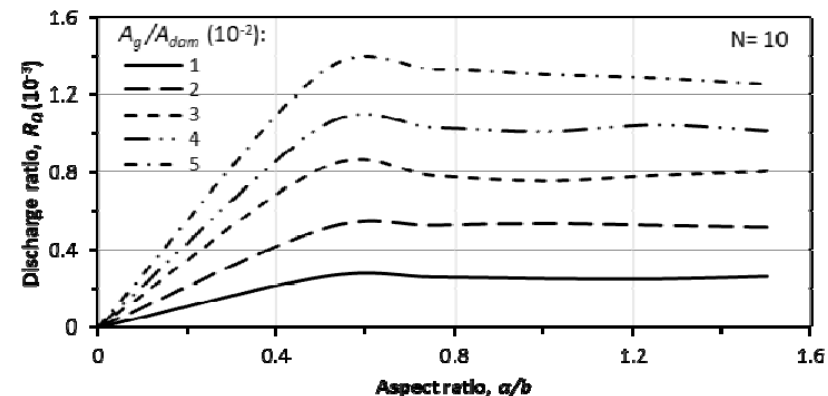

(a)

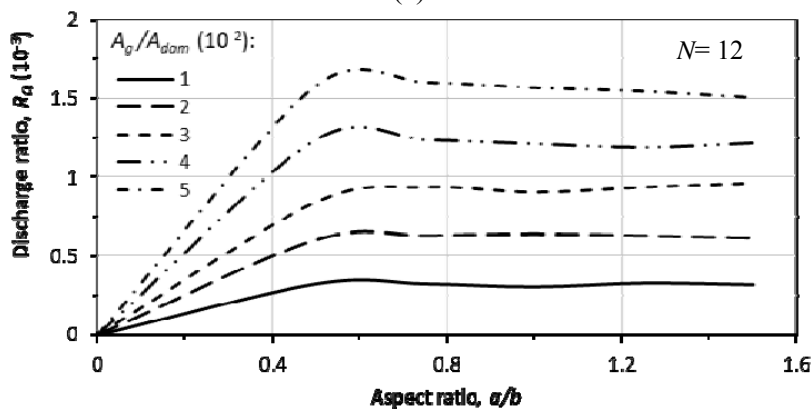

(b)

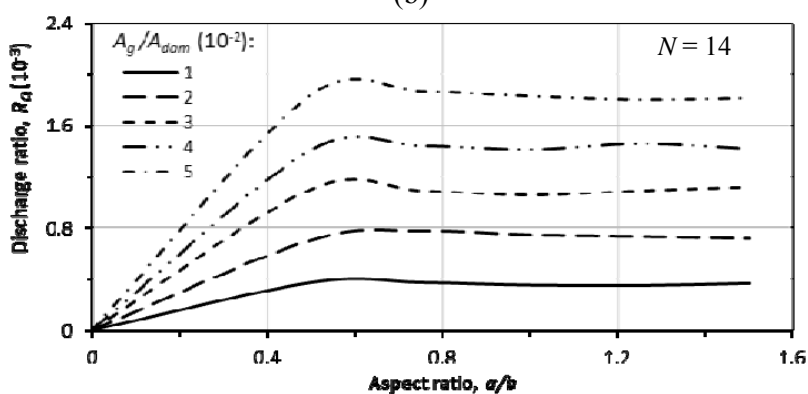

(c)

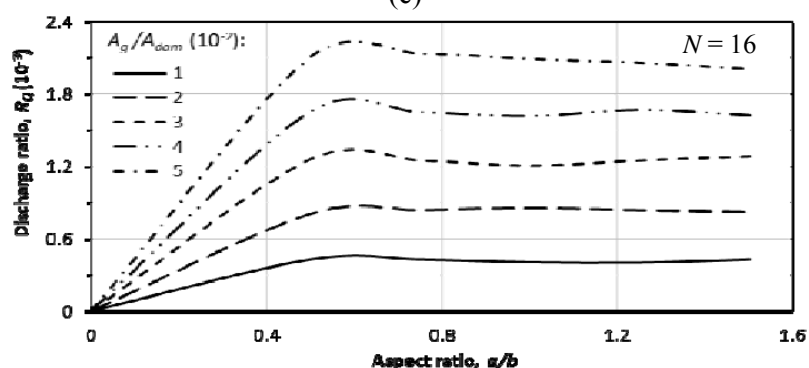

(d)

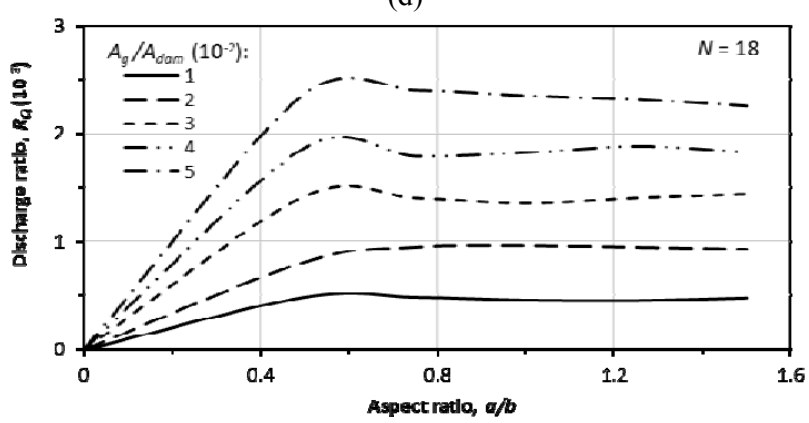

(e)

Fig.5 Variation of discharge ratio $R_{Q}$ with aspect ratio $a / b$ for different values of number of gates $N$ as: (a) 10 , (b) 12 , (c) 14 , (d) 16 , and (e) 18 .

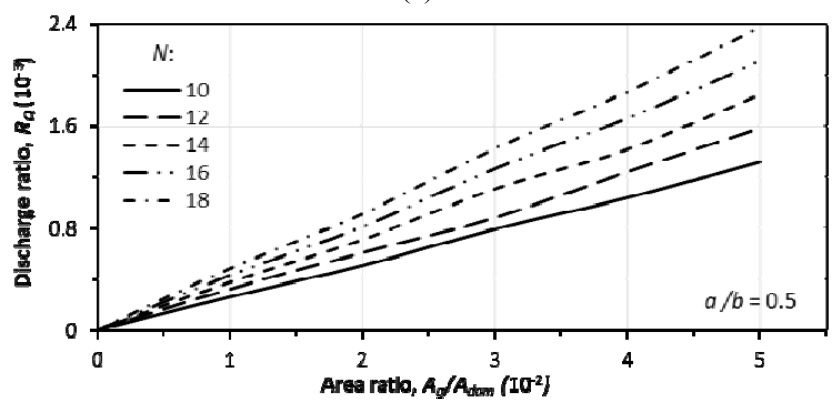

(a)

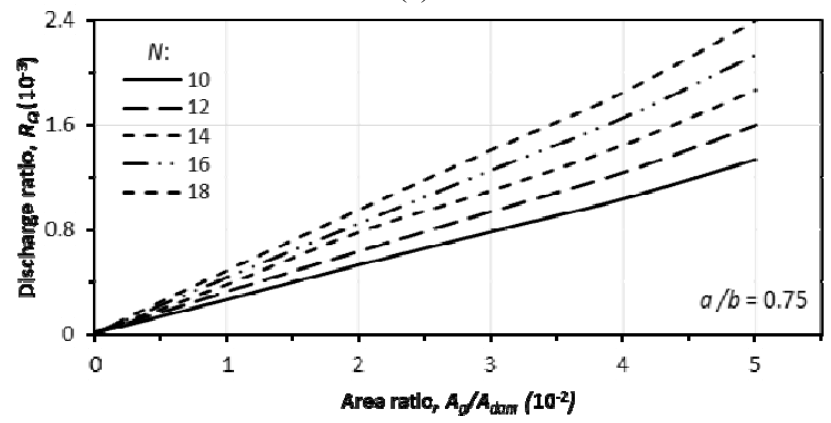

(b)

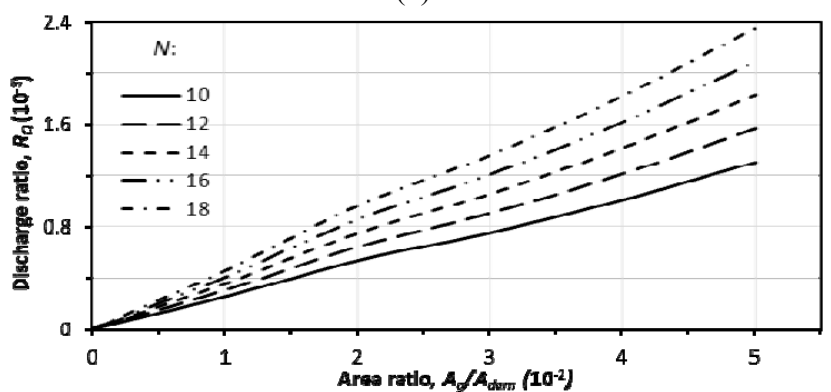

(c)

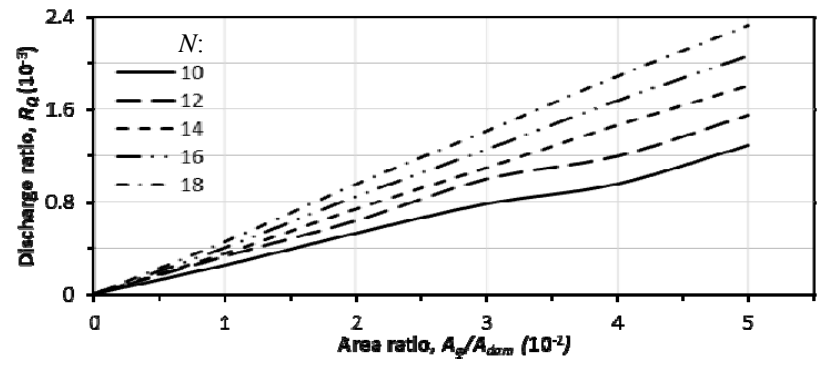

(d)

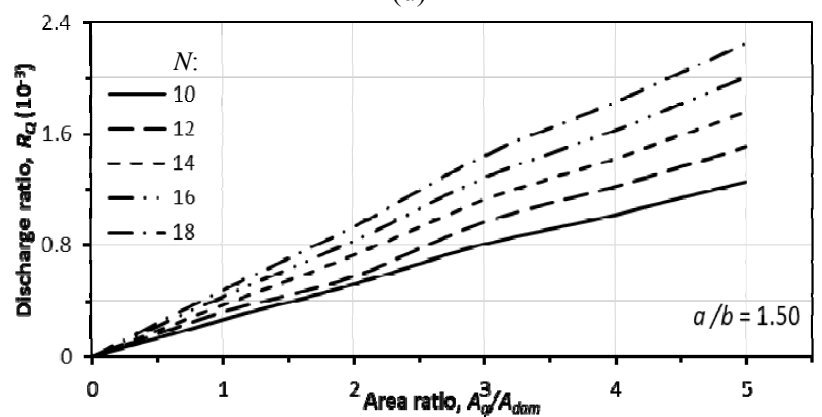

(e) 
Fig.6. Variation of discharge ratio $R_{Q}$ with area ratio $R_{A}$ for different values of aspect ratio $(a / b)$ as: (a) 0.5 , (b) 0.75 , (c) 1.0 , (d) 1.25 , and (e) 1.5 .

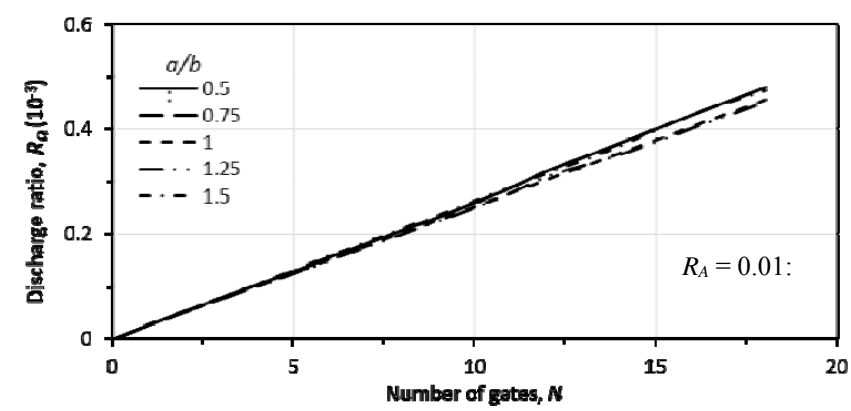

(a)

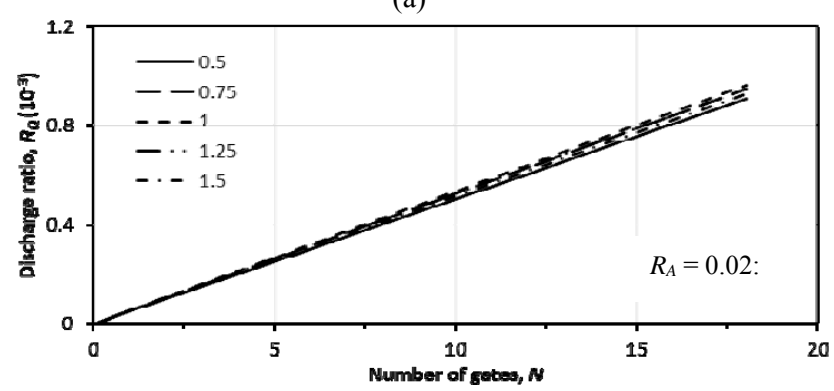

(b)

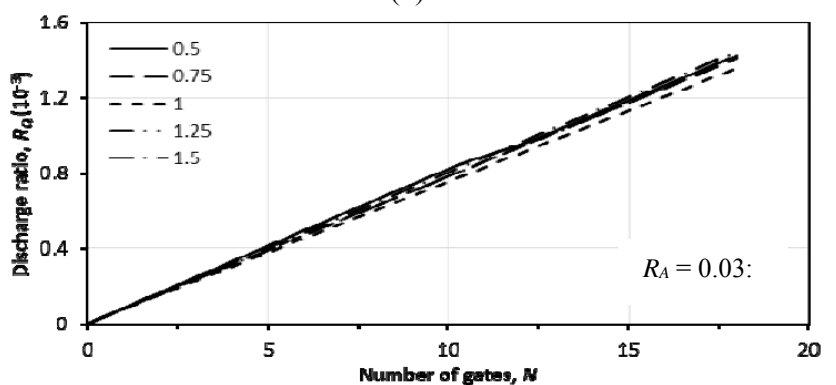

(c)

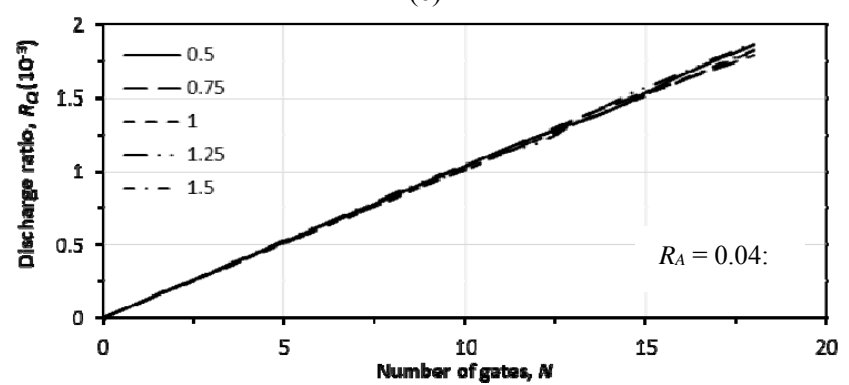

(d)

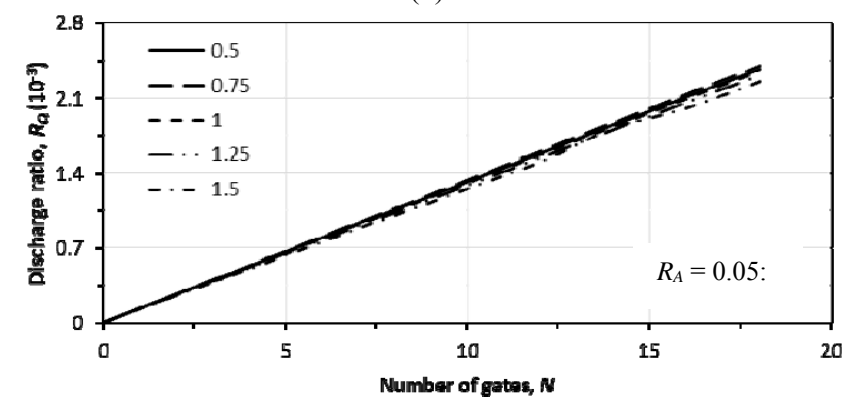

(e)
Fig.7. Variation of discharge ratio $R_{Q}$ with number of gates $N$ for different values of area ratio $\left(R_{A}\right)$ as: a) 0.01 , (b) 0.02 , (c) 0.03 , (d) 0.04 , and (e) 0.05 .

\section{CONCLUSIONS}

The effectivity of sluice gates in controlling the discharge through a gravity dam has been investigated in this paper by means of simplified analytical methodology. The model has been applied successfully to a specific case study at a site in western India and important observations were found there from.

The study reveals that the discharge ratio increases linearly with the aspect ratio till a peak value is attained and thereafter stabilizes. The peak value was observed to occur $a / b=0.5$. With respect to the area ratio and the number of gates, the discharge ratio increased fairly linearly, commencing from the origin with progressive diverging trends.

\section{ACKNOWLEDGMENT}

The authors thankfully acknowledge the in-kind support received from the Department of Civil Engineering, Assam Kaziranga University, Jorhat, Assam, India, during analysis and interpretations of this work. The manuscript is prepared with the infrastructure supports received from Eliitte College of Engineering, Sodepur, Kolkata, India.

\section{NOTATIONS}

The following notations are used in this article:

A $=$ Height of the sluice gate.

$a / b=$ Aspect ratio of the gate.

$b=$ Width of the gate.

$C_{c}=$ Coefficient of contraction.

$C_{d}=$ Coefficient of discharge.

$H$ = Height of the dam.

$L \quad=$ Length of the dam.

$N=$ Number of gates.

$Q_{0}=$ Discharge through dam.

$Q_{\text {gate }}=$ Discharge through sluice gates.

$R_{A}=$ Area ratio of the dam.

$R_{Q}=$ Discharge ratio of the dam.

$v \quad=$ Reference velocity.

$y \quad=$ Opening of the sluice gate.

\section{REFERENCES}

[1] H. R. Henry, "Discussion of diffusion of submerged jets," Trans. Proc. ASCE, vol. 115, pp. 687-697, 1950.

[2] S. Panda, "Characteristics of side sluice flow." ME thesis, University of Roorkee, India, 1981.

[3] N. Rajaratnam, and K. Subramanya, "Flow equation for the sluice gate," J. Irrigation and Drainage Eng., vol. 93, no. 4, pp. 167-186, 1967.

[4] M. P. S.Tanwar, "Flow through side sluice," ME thesis, University of Roorkee, India, 1984.

[5] P. K. Swamee, S. K. Pathak, and M. S. Ali, "Analysis of rectangular side sluice gate," J. Irrigation and Drainage Eng., vol. 119, no. 6, pp. 1026$1035,1993$.

[6] P. K.Swamee, "Sluice gate discharge equations," J. Irrigation and Drainage Eng., vol. 118, no. 1, pp. 56-60, 1992. 
[7] N. Abdelazim, "Characteristics of combined flow over weirs and below gates," Sudan Engineering Society J., vol. 44, pp. 30-37, 1997.

[8] A. K. Bhattachrya, S. Basack, and G. Bhattacharya, "Reduction of local scour around non-cylindrical bridge piers at high angles of attack using collar," ISH J. Hydraulic Eng., vol. 9, no. 2, pp. 1-10, 2004.

[9] B. J. Binder, "A non-linear dynamical system: flow past a sluice gate," Australasian J. Eng. Education, vol. 15, no. 2, pp. 27-34, 2009.

[10] C. Spulveda, M. Gomez, and J. Rodellar, "Benchmark of discharge calibration methods for submerged sluice gates," J. Irrigation and Drainage Eng., vol. 135, no. 5, pp. 676-682, 2009.

[11] F. Daneshmand, S. A. S. Javanmard, T. Liaghat, M. M. Moshksar, and J. F. Adamowski, "Numerical solution for two-dimensional flow under sluice gates using the natural element method," Canadian J. Civil Eng., vol. 37, pp. 1550-1559, 2010.

[12] A. Goel, "Scour investigations behind a vertical sluice gate without apron," Pacific J. Science and Technology, vol. 11, no. 2, pp. 59-65, 2010 .

[13] T. Mansoor, "Free flow below skew sluice gate," Int. J. Eng. Research and Development, vol. 10, no. 3, pp. 44-52, 2014.

[14] Francesco Gallerano, Giovanni Cannata, Marco Tamburrino, Simone Ferrari, Maria Grazia Badas, Giorgio Querzoli, Water Waves Overtopping Over Barriers, WSEAS Transactions on Fluid Mechanics, Volume 14, 2019, pp. 84-91

[15] Francesco Gallerano, Giovanni Cannata, Luca Barsi, Federica Palleschi, Benedetta Iele, Simulation of Wave Motion and Wave Breaking Induced Energy Dissipation, WSEAS Transactions on Fluid Mechanics, Volume 14, 2019, pp. 62-69

[16] S. Basack, A. K. Bhattacharya, and P. Maity, "A coastal groundwater management model with Indian case study," Proc. Institution of Civil Engineers: Water Management, vol. 167, no. 3, pp. 126-140, 2014.

[17] G. Goswami, D. Ther, D. Patel, P. Budhe, M. Vidwans., M. Asati, S. Chaudhari, A. Dharkar, and Tembhre, "Assessment of Environmental Flow, "BE thesis, Manoharbhai Patel Institute of Engineering and Technology, Nagpur University, Maharashtra, India, 2017.

[18] H. Rouse, "Laws of transportation of sediment by streams," Suspended Load, Reprint No. 21, University of Iowa, USA, 1939.

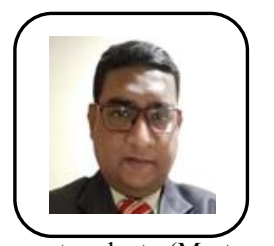

Sudip Basack, PhD, FIE, M.ASCE is a PhD in Civil Engineering and has vast academic experience at responsible senior positions in India and abroad. He published more than 100 technical papers in reputed journals and conferences and is recipient of several research awards at national and international levels. He has supervised more than 10 research students at postgraduate (Masters and $\mathrm{PhD}$ ) levels and successfully implemented several sponsored research projects in different Universities. He has undertaken academic visits in many countries including USA, UK, Germany, Australia, New Zealand, Singapore, China, etc.

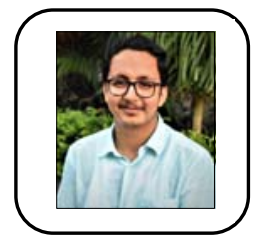

Ghritartha Goswami, BE, M.Tech. is a Professiona civil and water resources engineer and currently an Assistant Professor at Scholar's Institute of Technology and Management, Guwahti, Assam, India. He graduated in civil engineering in the year of 2017 from Nagpur University, Maharashtra, India and post-graduated in water resources engineering in the year of 2019 from Assam Kaziranga University, Jorhat, Assam, India. He has participated in various renowned conferences and presented papers.

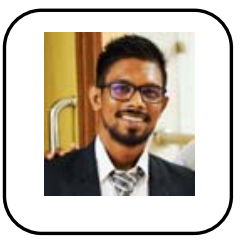

Prandeep Deka, B.Tech. is currently working as the Designated Assistant Manager at Extramarks Education India Private Limited.Kaziranga University, Jorhat, Assam, India. He graduated in civil engineering in the year of 2019 from Assam Kaziranga University, Jorhat, Assam, India.

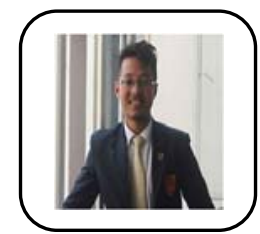

Partha Pratim Borah, B.Tech., graduated in civil engineering in the year 2019 from Assam Kaziranga University, Jorhat, Assam, India. He was selected for Master's program in Transport and Geo-information Technology at K.T.H Royal Institute of Technology in Stockholm, Sweden. He is the co-founder of multi delivery startup service - EKO DELIVERY.

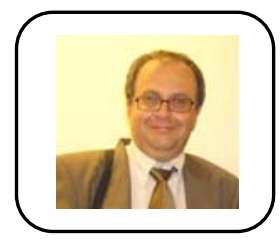

Nikos Mastorakis studied Medicine in the University of Athens 1982-1984 and 1988-1992. He received the Diploma (B.Sc.+M.Sc) of Electrical Engineering from the National Technical University of Athens with grade "Excellent" (9.33) in 1988, and the B.Sc. in Mathematics with grade "Excellent" (8.65) from the National and Kapodistrian University of Athens, Department of Mathematics in 1995. In 1992 he received his Ph.D. in Electrical Engineering and Applied Mathematics with grade "Excellent" (10) from the National Technical University of Athens.

Academic Positions:

a) Professor at National Technical University of Sofia, Bulgaria since 2008, b) Professor Military Institutes of University Education (ASEI), Hellenic Naval Academy (HNA) since 1996,

c) Visiting Professor at the University of Exeter, United Kingdom, 1998-1999, d) Visiting Professor at the National Technical University of Sofia, Bulgaria, 2002-2003

e) Visiting Professor at the National Technical University of Sofia, Bulgaria, 2007-2008,

f) Honorary Professor at the Technical University of Cluj-Napoca, Romania, since 2008

g) Prize of Excellence and Honorary Professor in the Romanian Academy of Science, Bucharest, 2008,

f) Honorary Professor at the Budapest Tech, Budapest, Hungary since 2009

g) Honorary Professor at the Obuda University, Budapest, Hungary since 2011

h) Visiting Professor, University of Salerno, Salerno, Italy, 2014-2015

$\mathrm{He}$ is an active researcher in Systems Theory, Computers, Environment amd Mechanics. He is among the Seven Greek researchers among the overproductive ones in the world according the Professor John Ioannides (Stanford University of California Medical School) https://www.ellines.com/en/good-news/41299-seven-greekresearchers-among-the-over-productive-ones-in-the-world/ with many papers and many citations. 